\title{
Prevalence of Dyspnea and its Associated Factors in Patients with Chronic Obstructive Pulmonary Disease
}

\author{
Sita Sharma, Pramod Sharma ${ }^{1}$ \\ Department of Nursing, Matron, Neuro Cardio and Multispecialty Hospital, Biratnagar, Nepal, ${ }^{1}$ Research Fellow, School of Allied Health Sciences, Griffith University, \\ Gold Coast, QLD, Australia
}

\section{Abstract}

Background: Dyspnea is highly distressing experience of breathlessness that limits the activities of daily living and affects an increasingly large group of patients with respiratory diseases such as chronic obstructive pulmonary disease (COPD). Aims: The aim of our study was to investigate the prevalence of dyspnea and its associated factors in patients with COPD. Patients and Methods: This cross-sectional study was carried out among 221 COPD patients of Tribhuvan University Teaching Hospital, Nepal. Patients' dyspnea was assessed using the modified Medical Research Council Dyspnea Scale and Dyspnea 12 Questionnaire. Patient's anxiety and depression were measured using Hospital Anxiety and Depression Scale, and COPD Assessment Test (CAT) was used to measure the impact of COPD. Mann-Whitney and Kruskal-Wallis test were used to find out the association between variables. Multiple regression analysis was used to find out the most significant factor associated with dyspnea. Results: Out of 221 patients, almost all $(92.8 \%)$ patients had some degrees of dyspnea. Dyspnea was statistically significantly associated with age $(P<0.001)$, education $(P<0.001)$, marital status $(P<0.001)$, type of family $(P=0.009)$, working status $(P<0.001)$, duration of illness $(P<0.001)$, history of previous hospitalization $(P<0.001)$, status of hospitalization in the last year $(P<0.001)$, domiciliary oxygen therapy $(P<0.001)$, other comorbidities $(P<0.001)$, anxiety $(P<0.001)$, and depression $(P<0.001)$. Conclusions: This study concludes that dyspnea is highly prevalent in COPD, and duration of illness, depression, and CAT score were the most significant factors associated with dyspnea in patients with COPD.

Keywords: Anxiety, chronic obstructive pulmonary disease, depression, dyspnea, factors, prevalence

\section{INTRODUCTION}

Dyspnea is a sensation of discomfort and distress associated with breathing. ${ }^{[1]}$ It is a cardinal symptom experienced by patients with heart and lungs' disease. Although dyspnea is associated with a range of cardiorespiratory disease, it is particularly significant in chronic obstructive pulmonary disease (COPD), causing considerable limitations to functional status and quality of life as well as a considerable socioeconomic burden. ${ }^{[2]}$

The American Thoracic Society defines dyspnea as "a subjective experience of breathing discomfort that consists of qualitatively distinct sensations that vary in intensity." ${ }^{[3]}$ These sensations are believed to originate from interactions among multiple physiological, social, psychological, and environmental factors. However, the extent to which these factors interact is not understood. ${ }^{[4-6]}$

Despite being extremely debilitating symptom, currently no effective treatment is available due to the limited understanding

\begin{tabular}{|l|l|}
\hline \multicolumn{2}{|c|}{ Access this article online } \\
\hline Quick Response Code: & Website: \\
\hline & www.ijrconline.org \\
\cline { 2 - 2 } & \\
\hline
\end{tabular}

of mechanisms underlying this symptom. Little can be done to treat underlying cause as moderate-to-severe COPD as they are usually irreversible. ${ }^{[3,7]}$

The experience of dyspnea is thought to be influenced by activity at many levels of the nervous system including the respiratory centers in the medulla and the cortex and structures within the limbic system. ${ }^{[7,8]}$ Many factors such as gender, history of smoking, a family history of respiratory disease, exposure to passive smoking, duration of disease, repeated hospitalization, other comorbidities, and oral corticosteroid therapy can influence the interpretation and quality of dyspnea, but there is limited evidence regarding this in the majority of countries..$^{[9-12]}$

Address for correspondence: Ms. Sita Sharma, Neuro Cardio and Multispecialty Hospital, Biratnagar, Nepal. E-mail: sharma.sita67@gmail.com

This is an open access journal, and articles are distributed under the terms of the Creative Commons Attribution-NonCommercial-ShareAlike 4.0 License, which allows others to remix, tweak, and build upon the work non-commercially, as long as appropriate credit is given and the new creations are licensed under the identical terms.

For reprints contact: reprints@medknow.com

How to cite this article: Sharma S, Sharma P. Prevalence of dyspnea and its associated factors in patients with chronic obstructive pulmonary disease. Indian J Respir Care 2019;8:36-41 
The objective of this study was to report the prevalence of moderate-to-severe dyspnea and explore its associated factors among patients with stable COPD.

\section{Patients and Methods}

This was a cross-sectional analytical study conducted at the Outpatient Department (OPD) of Tribhuvan University Teaching Hospital (TUTH), Kathmandu, Nepal. The total duration of study was 12 weeks. Clinically stable COPD patients visited at TUTH were considered eligible and invited to take part in the study. Informed consent was obtained from each COPD patient before data collection who met the inclusion criteria. They wee informed that their participation was voluntary and there was no foreseeable risk or harm involved with the study. Patients were also assured that their confidentiality will be maintained using code number in all forms, and information obtained will solely be used for research purpose. Patients were given liberty to discontinue participating in the study without any clarification.

At first, the OPD record card was reviewed for confirmation of the diagnosis. Data were collected by researcher herself through face-to-face interview method. Privacy was maintained by carrying out the data collection procedure from each participant separately and in a separate room of the OPD of TUTH. General information related to demographic, socioeconomic, and treatment-related information was collected by interviewing with the respondent. After that, validated questionnaires of dyspnea (modified Medical Research Council [mMRC] Dyspnea Scale and Dyspnea-12 Questionnaire), health impairment (COPD Assessment Test [CAT]), and Hospital Anxiety and Depression Scale were applied. In this study, patients with acute exacerbation, acute chest infection, heart disease, and severe case of COPD were excluded from the study. Clinical stability was defined as the absence of exacerbation for the previous 4 weeks.

The collected data were checked daily and organized for completeness and accuracy. The data were then edited, coded, classified, and then entered into Excel spreadsheet, which was later transferred to Statistical Package for the Social Sciences version 24 (IBM). Descriptive statistics such as frequency and percentages were used for categorical variables and mean and standard deviation were used for continuous variables. The relationship of various factors with dyspnea was analyzed using Mann-Whitney test and Kruskal-Wallis test. Multiple regression was done to find out the most significant associated factor for dyspnea. The significance level was set at $P<0.05$ and $95 \%$ confidence interval.

This study was approved by the Research Committee Maharajgunj Nursing Campus and Institutional Review Board of Tribhuvan University, Institute of Medicine, Kathmandu, Nepal.

\section{RESULTS}

A total of 221 patients constituted the study population. The mean age of patients with COPD was $66.15 \pm 10.14$ years that ranged between 44 and 90 years. More than half of the patients $(53.8 \%)$ were female. Similarly, $35.3 \%$ of COPD patients were literate. Most of the COPD patients $(67.4 \%)$ were married and majority of the patients $(76 \%)$ were living with their children in joint family. Similarly, $61.1 \%$ of patient's household income was low. Regarding occupation, majority of the patients $(76.9 \%)$ were not currently involved in any occupation. About $62.9 \%$ of COPD patients were former smokers. Similarly, more than half $(57.5 \%)$ of the patients had no history of exposure to passive smoking. Likewise, half of the COPD patient's $(50.7 \%)$ duration of illness was $<5$ years. Mean duration of illness was $6.99 \pm 6.34$ days. More than half of the COPD patients (57\%) had been hospitalised previously and $48.4 \%$ were hospitalized once in the last year. Among COPD patients, $20.8 \%$ required domiciliary oxygen and $24 \%$ had other comorbidities such as hypertension, diabetes, benign prostate hypertrophy, and others.

Perceived level of dyspnea of COPD patients was measured by the mMRC Dyspnea Scale. Almost all (92.8\%) patients had some degrees of dyspnea. Most of the COPD patients $(72 \%)$ had $\mathrm{mMRC}$ dyspnea score $\geq 2$. Among the total patients, $32.6 \%$ patients had dyspnea Grade 3, i.e., patients had to stop for breath after walking about $100 \mathrm{~m}$ or after a few minutes on the level and $7.2 \%$ of patients had dyspnea Grade 0, i.e., patients had developed dyspnea only during strenuous exercise [Table 1].

Similarly, in physical dimension of Dyspnea-12 Questionnaire, most of the COPD patients had moderate (Score 3) level in all descriptors such as their breathing does not go in all the way, breathing requires more work, feeling short of breath, difficulty in catching breath, not getting enough air, uncomfortable breathing, and exhausting breathing. Similarly, 38.9\% of patients reported that breathing makes them feel moderately depressed, $37.1 \%$ felt that breathing makes them feel mildly miserable, $40.7 \%$ had moderate distress during breathing, $27.1 \%$ had no agitation in breathing while $31.7 \%$ had mild irritating breathing. Difficulty in catching breath was the commonest symptom [Table 2].

Mann-Whitney U-test and Kruskal-Wallis test were used to find the differences of dyspnea mean score between

\begin{tabular}{|c|c|c|}
\hline Item description & Grade & $n(\%)$ \\
\hline I only get breathless with strenuous exercise & 0 & $16(7.2)$ \\
\hline $\begin{array}{l}\text { I get shortness of breath when hurrying on the } \\
\text { level or walking up a slight hill }\end{array}$ & 1 & $46(20.8)$ \\
\hline $\begin{array}{l}\text { I walk slower than people of the same age on the } \\
\text { level because of breathlessness or have to stop for } \\
\text { breath when walking at my own pace on the level }\end{array}$ & 2 & $41(18.6)$ \\
\hline $\begin{array}{l}\text { I stop for breath after walking about } 100 \text { meters } \\
\text { or after a few minutes on the level }\end{array}$ & 3 & $72(32.6)$ \\
\hline $\begin{array}{l}\text { I am too breathless to leave the house or I am } \\
\text { breathless when dressing }\end{array}$ & 4 & $46(20.8)$ \\
\hline
\end{tabular}


Sharma and Sharma: Dyspnea in patient with COPD

different groups. This analysis showed that dyspnea score was higher in age 70 and more $(P<0.001)$, in males but statistically not significant, higher among illiterate $(P<0.001)$, widow and widower $(P<0.001)$, joint family $(P=0.009)$, not currently employed $(P<0.001)$, duration of illness 10 years and more $(P<0.001)$, history of previous hospitalization $(P<0.001)$, more than once hospitalization in the last year $(P<0.001)$, patient with domiciliary oxygen therapy $(P<0.001)$, and patient having other comorbidities $(P<0.001)$. Similarly, dyspnea mean score is higher among patient with anxiety $(P<0.001)$ and patient with depression $(P<0.001)$ [Tables 3 and 4 ].
Likewise, the association of dyspnea with CAT score measured by Spearman's correlation revealed that there was a strong positive correlation between dyspnea and CAT score $(r=0.75, P<0.001)$ [Table 5].

A multiple regression analysis was done to predict dyspnea from age, educational status, marital status, type of family, occupational status, duration of illness, history of previous hospitalization, number of hospitalization in the last year, use of domiciliary oxygen therapy, presence of other comorbidities, anxiety, depression, and CAT score. These variables statistically significantly predicted mMRC score,

\begin{tabular}{|c|c|c|c|c|c|}
\hline Item description & None $\mathbf{0}, \boldsymbol{n}(\%)$ & Mild 1, $n(\%)$ & Moderate 2, n (\%) & Severe 3, $n(\%)$ & Mean \pm SD \\
\hline My breath does not go in all the way & $65(29.3)$ & $62(28.1)$ & $68(30.8)$ & $26(11.8)$ & $1.24 \pm 1.00$ \\
\hline My breathing requires more work & $46(20.8)$ & $67(30.3)$ & $79(35.7)$ & $29(13.2)$ & $1.41 \pm 0.96$ \\
\hline I feel short of breath & $53(24.0)$ & $61(27.6)$ & $75(33.9)$ & $32(14.5)$ & $1.39 \pm 1.00$ \\
\hline I have difficulty catching my breath & $23(10.4)$ & $72(32.6)$ & $83(37.5)$ & $43(19.5)$ & $1.66 \pm 0.90$ \\
\hline I cannot get enough air & $65(29.4)$ & $59(26.7)$ & $70(31.7)$ & $27(12.2)$ & $1.27 \pm 1.01$ \\
\hline My breathing is uncomfortable & $25(11.3)$ & $78(35.3)$ & $94(42.5)$ & $24(10.9)$ & $1.53 \pm 0.83$ \\
\hline My breathing is exhausting & $45(20.4)$ & $67(30.3)$ & $88(39.8)$ & $21(9.5)$ & $1.38 \pm 0.91$ \\
\hline My breathing makes me feel depressed & $47(21.3)$ & $72(32.6)$ & $86(38.9)$ & $16(7.2)$ & $1.32 \pm 0.89$ \\
\hline My breathing makes me feel miserable & $41(18.6)$ & $82(37.1)$ & $78(35.3)$ & $20(9.0)$ & $1.35 \pm 0.88$ \\
\hline My breathing is distressing & $31(14.0)$ & $72(32.6)$ & $89(40.3)$ & $29(13.1)$ & $1.52 \pm 0.89$ \\
\hline My breathing makes me agitated & $60(27.1)$ & $57(25.8)$ & $59(26.7)$ & $45(20.4)$ & $1.40 \pm 1.09$ \\
\hline My breathing is irritating & $54(24.4)$ & $70(31.7)$ & $66(29.9)$ & $31(14.0)$ & $1.33 \pm 0.99$ \\
\hline
\end{tabular}

SD: Standard deviation

Table 3: Association of dyspnea with sociodemographic characteristics $(n=221)$

\begin{tabular}{|c|c|c|c|c|}
\hline Characteristics & Frequency & Mean rank & Mann-Whitney U-test/Kruskal-Wallis value & $P$ \\
\hline \multicolumn{5}{|l|}{ Age (years) } \\
\hline$<60$ & 62 & 89.01 & $21.594^{\mathrm{b}}$ & $<0.001 *$ \\
\hline $60-69$ & 82 & 103.95 & & \\
\hline 70 and more & 77 & 136.22 & & \\
\hline \multicolumn{5}{|l|}{ Gender } \\
\hline Male & 102 & 114.97 & $5664.50^{\mathrm{a}}$ & 0.379 \\
\hline Female & 119 & 107.60 & & \\
\hline \multicolumn{5}{|l|}{ Educational status } \\
\hline Literate & 78 & 96.14 & $4418.00^{\mathrm{a}}$ & $0.009^{*}$ \\
\hline Illiterate & 143 & 119.10 & & \\
\hline \multicolumn{5}{|l|}{ Marital status } \\
\hline Married & 149 & 97.63 & $21.25^{\mathrm{b}}$ & $<0.001^{*}$ \\
\hline Widow/widower & 72 & 138.67 & & \\
\hline \multicolumn{5}{|l|}{ Types of family } \\
\hline Nuclear & 53 & 91.47 & $3417.00^{\mathrm{a}}$ & $0.009 *$ \\
\hline Joint & 168 & 117.16 & & \\
\hline \multicolumn{5}{|c|}{ Current working status } \\
\hline Yes & 51 & 79.97 & $2752.50^{\mathrm{a}}$ & $<0.001 *$ \\
\hline No & 170 & 120.31 & & \\
\hline \multicolumn{5}{|l|}{ Smoking status } \\
\hline Current smoker & 34 & 105.68 & $3.15^{\mathrm{b}}$ & 0.207 \\
\hline Former smoker & 139 & 116.47 & & \\
\hline Non smoker & 48 & 98.93 & & \\
\hline
\end{tabular}


Sharma and Sharma: Dyspnea in patient with COPD

\begin{tabular}{|c|c|c|c|c|}
\hline Characteristics & Frequency & Mean rank & Mann-Whitney U-test/Kruskal-Wallis value & $P$ \\
\hline \multicolumn{5}{|c|}{ Duration of illness (years) } \\
\hline$<5$ & 112 & 86.63 & $21.577^{\mathrm{b}}$ & $<0.001 *$ \\
\hline $5-9$ & 60 & 109.67 & & \\
\hline 10 and more & 49 & 138.57 & & \\
\hline \multicolumn{5}{|c|}{ History of previous hospitalization } \\
\hline Yes & 126 & 125.81 & $4119.000^{\mathrm{a}}$ & $<0.001 *$ \\
\hline No & 95 & 91.36 & & \\
\hline \multicolumn{5}{|c|}{ Status of hospitalization in last year $(n=126)$} \\
\hline No hospitalization & 35 & 59.99 & $14.569^{\mathrm{b}}$ & $<0.001 *$ \\
\hline Once & 61 & 55.23 & & \\
\hline$>$ Once & 30 & 84.42 & & \\
\hline \multicolumn{5}{|l|}{ Steroid therapy } \\
\hline Yes & 26 & 109.10 & $2485.500^{\mathrm{a}}$ & 0.868 \\
\hline No & 195 & 111.25 & & \\
\hline \multicolumn{5}{|c|}{ Domiciliary oxygen therapy } \\
\hline Yes & 46 & 163.42 & $1613.500^{\mathrm{a}}$ & $<0.001 *$ \\
\hline No & 175 & 97.22 & & \\
\hline \multicolumn{5}{|l|}{ Other comorbidities } \\
\hline Present & 53 & 140.56 & $2885.500^{\mathrm{a}}$ & $<0.001 *$ \\
\hline Absent & 168 & 101.68 & & \\
\hline \multicolumn{5}{|l|}{ Anxiety } \\
\hline Present & 140 & 139.76 & $1643.000^{\mathrm{a}}$ & $<0.001 *$ \\
\hline Absent & 81 & 61.28 & & \\
\hline \multicolumn{5}{|l|}{ Depression } \\
\hline Present & 148 & 138.40 & 1347.000 & $<0.001 *$ \\
\hline Absent & 73 & 55.45 & & \\
\hline
\end{tabular}

*P significant at $\leq 0.05,{ }^{a}$ Mann-Whiteny U-test, ${ }^{b}$ Krukal-Wallis test

Table 5: Association of dyspnea with chronic obstructive pulmonary disease assessment test score in chronic obstructive pulmonary disease patients $(n=221)$

\begin{tabular}{lcccc}
\hline Variables & Mean value & SD & $\boldsymbol{r}_{\text {s }}$ value & $\boldsymbol{P}$ \\
\hline CAT score & 11.37 & 6.89 & 0.75 & $<0.001 *$ \\
\hline$* P$ significant at $\leq 0.05 . r_{\mathrm{s}}$ : Spearman rank correlation, SD: Standard \\
deviation, CAT: COPD assessment test, COPD: Chronic obstructive \\
pulmonary disease
\end{tabular}

$F(12,113)=30.400, P<0.0005$, and $R^{2}=0.764$. Variables, such as duration of illness $(P=0.036)$, depression $(P<0.0005)$, and CAT score $(P<0.0005)$, were the most significant factors associated with dyspnea [Table 6].

\section{Discussion}

In this study, we assessed the dyspnea level using two standard tools, i.e., mMRC Dyspnea Scale and Dyspnea-12 Questionnaire. Results showed that almost all patients (92.8\%) felt some degree of dyspnea and most of the COPD patients $(72 \%)$ reported moderate or severe dyspnea (mMRC score $\geq 2$ ). Among the COPD patients, $32.6 \%$ of patients had mMRC dyspnea Grade "3," meaning that "the patient had to stop for breath after walking about $100 \mathrm{~m}$ or after a few minutes on the level" and $7.2 \%$ of patients had mMRC dyspnea Grade 0, i.e., patient had developed dyspnea "only during strenuous exercise." Barnes et al., in contrast reported that $38 \%$ of their patients were classified as $\mathrm{mMRC} \geq 2 .{ }^{[13]}$ Similarly, Mullerova et al. and Punekar et al. reported that $40 \%$ and $47.3 \%$ of their patients respectively, reported moderate or severe dyspnea ${ }^{[6,12]}$ The mean dyspnea score in this study was $2.38 \pm 1.22$, whereas study by Haruna et al. showed a mean dyspnea score as $1.1 \pm 0.8 .^{[14]}$

Association of sociodemographic characteristics of dyspnea revealed that dyspnea was significantly associated with age $(P<0.001)$. These findings are supported by Bestall et al., (1999) who showed that age had the highest level of association $(P<0.005)$ with MRC grade. ${ }^{[15]}$ The findings of the present study showed no statistically significant association between gender and dyspnea level. This result is contrast to the findings by Guenette et al., and Koblizek et al. which showed women with COPD had significantly greater dyspnea than men. ${ }^{[16,17]}$ A study by de Torres et al. also reported that, compared with men, women with COPD report more functional dyspnea for the same degree of airway obstruction. The values of $\mathrm{mMRC}$ were higher for women in all stages of the disease. Intergender difference was statistically significant $(P=0.028$, Chi-square test). ${ }^{[18]}$

Similarly, dyspnea level was higher among illiterate patient $(P<0.001)$, widow and widower patient $(P<0.001)$, and those who were living with their children in joint 
Sharma and Sharma: Dyspnea in patient with COPD

\begin{tabular}{|c|c|c|c|c|c|c|}
\hline \multirow[t]{2}{*}{ Variables } & \multirow[t]{2}{*}{$B$} & \multirow[t]{2}{*}{ SE } & \multirow[t]{2}{*}{ Adjusted OR ( $\beta$ ) } & \multicolumn{2}{|c|}{$95 \% \mathrm{Cl}$} & \multirow[t]{2}{*}{$P$} \\
\hline & & & & Lower & Upper & \\
\hline Age & -0.095 & 0.091 & -0.061 & -0.274 & 0.450 & 0.223 \\
\hline Education status & 0.138 & 0.128 & 0.053 & -1.116 & 0.391 & 0.297 \\
\hline Marital status & 0.026 & 0.063 & 0.023 & -0.099 & 0.151 & 0.677 \\
\hline Occupation & 0.260 & 0.173 & 0.080 & -0.083 & 0.602 & 0.136 \\
\hline Duration of illness & 0.019 & 0.009 & 0.109 & 0.001 & 0.036 & 0.036 \\
\hline Times & -0.048 & 0.072 & -0.033 & -0.190 & 0.094 & 0.502 \\
\hline Domiciliary oxygen therapy & -0.0267 & 0.139 & -0.111 & -0.543 & 0.008 & 0.057 \\
\hline Other comorbidities & -0.108 & 0.128 & -0.044 & -0.361 & 0.145 & 0.400 \\
\hline Anxiety & 0.010 & 0.018 & 0.061 & 0.589 & 0.631 & 0.557 \\
\hline Depression & 0.082 & 0.021 & 0.419 & 0.041 & 0.123 & $<0.001$ \\
\hline CAT score & 0.494 & 0.091 & 0.354 & 0.314 & 0.674 & $<0.001$ \\
\hline
\end{tabular}

SE: Standard error, OR: Odds ratio, CI: Confidence interval, CAT: COPD assessment test, COPD: Chronic obstructive pulmonary disease

family $(P=0.009)$. Similar findings were reported by Holm et $a$ l. that age was not associated with dyspnea among individuals who were in a couple relationship and more breathlessness was found in patients who were single. ${ }^{[19]}$

Furthermore, there was no statistically significant association between dyspnea and smoking status, exposure to passive smoking, and history of COPD in family. Regarding smoking status, Lu et al. (2012) have previously shown to present no association between smoking and dyspnea. ${ }^{[9]}$ However, this result is contrary to the finding of Roche et al. where dyspnea was significantly associated with smoking, a family history of respiratory disease, and exposure to passive smoking. ${ }^{[10]}$

This study showed dyspnea is significantly associated with duration of illness $(P<0.001)$, history of previous hospitalization $(P<0.001)$, and status of hospitalization in the last year $(P<0.001)$. These findings are in line with Bilgic et al. showing statistically significant difference between dyspnea and disease length (year) $(P<0.05)$ and repeated hospitalization $(P<0.01) .^{[11]}$

Similarly, there was also a significant association of dyspnea level with domiciliary oxygen therapy $(P<0.001)$ and other health problems $(P<0.001)$. These findings are supported by Punekar et al., who found association of dyspnea with long-term oxygen therapy $(P<0.0001)$ and Lu et al., (2012) found that a higher risk of more severe dyspnea was associated with most comorbid diagnoses. ${ }^{[9,12]}$

This study also explored that there was no association of steroid therapy with dyspnea. Whereas Lu et al. (2014) show contrast findings as there was a significant association of oral corticosteroid therapy with dyspnea $(P<0.0001) .{ }^{[9]}$

In this study, dyspnea mean score is higher among patient with anxiety $(P<0.001)$ and patient with depression $(P<0.001)$. And also, there was strong positive correlation between dyspnea and CAT score $(r=0.75, P<0.001)$. The current findings are supported by previous work of researcher, which shows the mMRC dyspnea score was significantly associated with anxiety and depression. ${ }^{[20]}$ Similarly, Gianjoppe-Santos et al. have shown that depression and anxiety symptoms had an association with dyspnea $(P=0.01) .{ }^{[21]}$ In contrary, Borges-Santos et al. found that dyspnea was associated with depression $(P<0.01)$ but not statistically associated with the anxiety $(P<0.77) .{ }^{[22]}$ Similarly, in some studies, the mMRC score displayed a moderate correlation with CAT score $(r=0.731, P<0.001) .{ }^{[23,24]}$

\section{Conclusions}

Patient's disease duration, presence of depression, and CAT score were the most significant factors that are associated with dyspnea in patient with COPD. Hence, these factors should be taken in consideration while managing dyspnea. Health promotion and educational interventions need to be intensified, and the educational intervention should focus on reducing or modifying those factors that have a direct impact on dyspnea.

\section{Acknowledgment}

We would like to thank University Grants Commission, Nepal, for supporting this study through a Masters Research Support grant 2017. We are also indebted to all the participants who showed interest in participating for this study.

\section{Financial support and sponsorship}

This study was financially supported by University Grants Commission, Nepal.

\section{Conflicts of interest}

There are no conflicts of interest.

\section{REFERENCES}

1. Manning HL, Schwartzstein RM. Pathophysiology of dyspnea. N Engl J Med 1995;333:1547-53.

2. Rabe KF, Hurd S, Anzueto A, Barnes PJ, Buist SA, Claverley P, et al. Global Initiative for Chronic Obstructive Lung Disease. Global strategy for the diagnosis, management, and prevention of chronic obstructive pulmonary disease: GOLD executive summary. Am J Respir Crit Care Med 2007;176:532-55.

3. Parshall MB, Schwartzstein RM, Adams L, Banzett RB, Manning HL, Bourbeau J, et al. An official American thoracic society statement: Update on the mechanisms, assessment, and management of dyspnea. 
Am J Respir Crit Care Med 2012;185:435-52.

4. Sharma P, Morris NR, Adams L. The effect of different exercise modalities on dyspnea and leg fatigue in healthy subjects. Respir Physiol Neurobiol 2015;210:44-50.

5. von Leupoldt A, Dahme B. Experimental comparison of dyspnea and pain. Behav Res0020Methods 2007;39:137-43.

6. Müllerová $\mathrm{H}, \mathrm{Lu} \mathrm{C}, \mathrm{Li} \mathrm{H}$, Tabberer M. Prevalence and burden of breathlessness in patients with chronic obstructive pulmonary disease managed in primary care. PLoS One 2014;9:e85540.

7. Sharma P, Morris NR, Adams L. Effect of experimental modulation of mood on perception of exertional dyspnea in healthy subjects. J Appl Physiol (1985) 2016;120:114-20.

8. von Leupoldt A, Dahme B. Psychological aspects in the perception of dyspnea in obstructive pulmonary diseases. Respir Med 2007;101:411-22.

9. Lu Y, Nyunt MS, Gwee X, Feng L, Feng L, Kua EH, et al. Life event stress and chronic obstructive pulmonary disease (COPD): Associations with mental well-being and quality of life in a population-based study. BMJ Open 2012;2:1-6.

10. Roche N, Perez T, Neukirch F, Carré P, Terrioux P, Pouchain D, et al. High prevalence of COPD symptoms in the general population contrasting with low awareness of the disease. Rev Mal Respir 2011;28:e58-65.

11. Bilgic Z, Tel H, Zorlu Z. Evaluation of Dyspnea and Fatigue Among the COPD Patients. Chronic Obstructive Pulmonary Disease - Current Concepts and Practice. Intechopen; 2010, 2020. p. 257-72.

12. Punekar YS, Mullerova H, Small M, Holbrook T, Wood R, Naya I, et al. Prevalence and burden of dyspnoea among patients with chronic obstructive pulmonary disease in five European countries. Pulm Ther 2016;2:59-72.

13. Barnes N, Calverley PM, Kaplan A, Rabe KF. Chronic obstructive pulmonary disease and exacerbations: Patient insights from the global hidden depths of COPD survey. BMC Pulm Med 2013;13:54.

14. Haruna A, Oga T, Muro S, Ohara T, Sato S, Marumo S, et al. Relationship between peripheral airway function and patient-reported outcomes in COPD: A cross-sectional study. BMC Pulm Med 2010;10:10.

15. Bestall JC, Paul EA, Garrod R, Garnham R, Jones PW, Wedzicha JA, et al. Usefulness of the medical research council (MRC) dyspnoea scale as a measure of disability in patients with chronic obstructive pulmonary disease. Thorax 1999;54:581-6.

16. Guenette JA, Jensen D, Webb KA, Ofir D, Raghavan N, O'Donnell DE, et al. Sex differences in exertional dyspnea in patients with mild COPD: Physiological mechanisms. Respir Physiol Neurobiol 2011;177:218-27.

17. Koblizek V, Pracharova S, Papousek P. Gender difference in the perception of dyspnea in former smokers with COPD. Eur Respir J 2011;38 Suppl 55:3576.

18. de Torres JP, Casanova C, Montejo de Garcini A, Aguirre-Jaime A, Celli BR. Gender and respiratory factors associated with dyspnea in chronic obstructive pulmonary disease. Respir Res 2007;8:18.

19. Holm KE, Plaufcan MR, Ford DW, Sandhaus RA, Strand M, Strange $\mathrm{C}$, et al. The impact of age on outcomes in chronic obstructive pulmonary disease differs by relationship status. J Behav Med 2014;37:654-63

20. Oga T, Tsukino M, Hajiro T, Ikeda A, Nishimura K. Analysis of longitudinal changes in dyspnea of patients with chronic obstructive pulmonary disease: An observational study. Respir Res 2012;13:85.

21. Gianjoppe-Santos J, Sentanin AC, Barusso MS, Rizzatti FP, Jamami M, Pires Di Lorenzo VA. Impact of exacerbation of COPD on anxiety and depression symptoms and dyspnea in the activities of daily living. Eur Respir J 2015;46 Suppl 59. Available from http://link.lis.curtin. edu.au/cgi-bin/ezproxy/ezpgateway.cgi?url=http://ovidsp.ovid.com/ ovidweb.cgi? $\mathrm{T}=\mathrm{JS} \& \mathrm{CSC}=\mathrm{Y} \& \mathrm{NEWS}=\mathrm{N} \& \mathrm{PAGE}=$ fulltext $\& \mathrm{D}=$ emed 17 $\& A N=72108226$. [Last retrieved on 2017 Feb 11].

22. Borges-Santos E, Wada JT, da Silva CM, Silva RA, Stelmach R, Carvalho CR, et al. Anxiety and depression are related to dyspnea and clinical control but not with thoracoabdominal mechanics in patients with COPD. Respir Physiol Neurobiol 2015;210:1-6.

23. Kim S, Oh J, Kim YI, Ban HJ, Kwon YS, Oh IJ, et al. Differences in classification of COPD group using COPD assessment test (CAT) or modified medical research council (mMRC) dyspnea scores: A cross-sectional analyses. BMC Pulm Med 2013;13:35.

24. Huang WC, Wu MF, Chen HC, Hsu JY, TOLD Group. Features of COPD patients by comparing CAT with mMRC: A retrospective, cross-sectional study. NPJ Prim Care Respir Med 2015;25:15063. 